\title{
A novel experimental method to characterise the shear strength of concrete based on pre-stressed samples. A comparison with existing techniques
}

\author{
Pascal Forquin ${ }^{1}$, Reem Abdul-Rahman ${ }^{1}$ and Dominique Saletti ${ }^{1}$ \\ ${ }^{1}$ Univ. Grenoble Alpes, CNRS, Grenoble INP, 3SR laboratory, 38100 Grenoble, France
}

\begin{abstract}
Mode II shear fracture process can be observed in plain-concrete structures exposed to intensive loadings such as shock, blasting or projectile-impact. It is the reason why the quasi-static and dynamic shear fracturing properties of concrete need to be investigated. In previous works performed by Forquin and coauthors a passive confining cell was applied to PTS (Punch-Through-Shear) specimens in a similar way than in quasi-oedometric compression tests where metallic ring are used as passive confinement. However the change of confining level during the sample loading constitutes a main drawback of this technique. In the present work a novel testing method is proposed based on a pre-stressing of the sample. To do so, the concrete specimen is inserted into pre-stressed metallic cell. During the unloading stage confining stresses are transferred to the ligament of the sample. In a second stage, a differential displacement applied to the central part of the sample toward the side parts produces a shearing of the ligament. The experiments performed in static and dynamic conditions (SHPB testing) allow the shear response of concrete to be determined over a wide range of strain-rates. In the present communication, the testing technique and obtained results are compared to the obtained data with the previous experimental method.
\end{abstract}

\section{Introduction}

When exposed to extreme loadings such as blasting or projectile-impact concrete structures as nuclear power plants, dams, bridges or bunkers suffer from intense tensile and shear damage modes as, for instance, cratering, multiple cracking, spall fracturing of shear failure [1-2]. For example, shear fracturing in mode II was identified in the confined zones of ultra-high strength concrete targets subjected to edge-on impact tests and normal impact tests [3-4]. When a massive target is impacted by a rigid projectile, triaxial compression and shear stresses are generated near the projectile noise, the confinement level being amplified by the inertia of the surrounding material. To improve the understanding and modelling of concrete behaviour under such confined shear loading, quasi-static and dynamic shear tests needs to be developed.

In the last decades, the Punch Through Shear (PTS) experimental technique was proposed by Watkins [5]. Two cylindrical notches are machined on the top and bottom faces of a concrete sample. The specimen is first subjected to a pure hydrostatic pressure whereas an axial load is added in a second step to create a shear fracturing of the ligament. This technique was more recently used by Montenegro et al [6] to evaluate the fracture energy of concrete as function of the hydrostatic pressure. More recently, a passive confining cell was used instead of hydraulic pressure to apply a confinement to the PTS specimen (Fig. 1) in a similar way than in quasioedometric compression tests [7-8]. This testing technique, named oedo-PTS, allowed the quasi-static and dynamic shear behaviour of dry and wet common concrete to be investigated $[9,10]$.

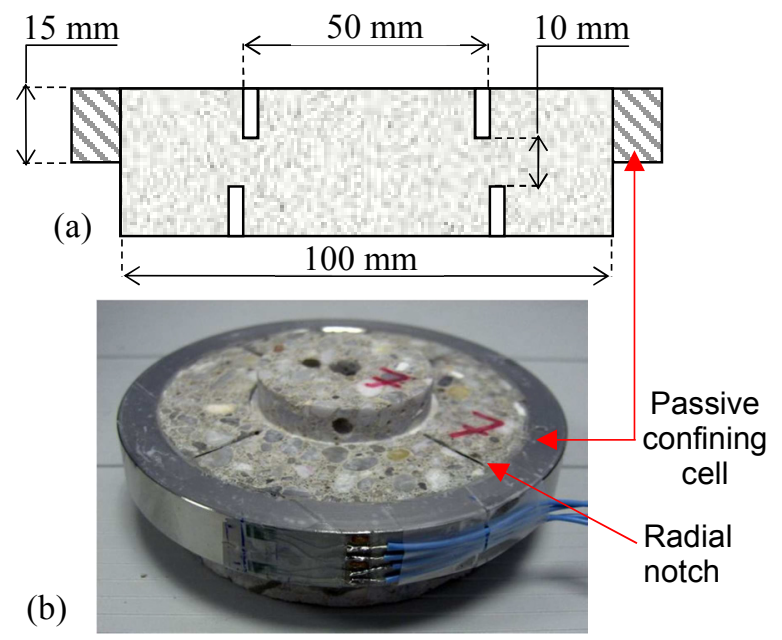

Fig. 1. (a) Geometry of sample and confining cell used in oedo-PTS test [9-10]. (b) Concrete sample after test.

A picture of a concrete sample is shown in Fig. $1 \mathrm{~b}$. Radial notches are performed in the sample to prevent any self-confinement of the external part of the sample, so the level radial stress in the ligament can be deduced from the hoop strain measured on the outer surface of the metallic confining ring. This experimental method was successfully employed to characterise the shear strength of common concrete [9-10] and ultra-high performance

Corresponding author: pascal.forquin@3sr-grenoble.fr 
concrete [11]. The results of a quasi-static oedo-PTS and dynamic oedo-PTS tests are depicted on the Fig. 2 and 3. The maximum levels of shear stress reached during these static and dynamic tests are respectively $54 \mathrm{MPa}$ and 67 $\mathrm{MPa}$. However this technique suffers from limitations and drawbacks. The main inconvenient is certainly that the confinement level rapidly changes from zero to a maximum level reached after the peak of shear stress (Fig. 2). The level of radial stress reached at the peak of the shear stress is about $27 \mathrm{MPa}$ in the static test and about $55 \mathrm{MPa}$ in the dynamic test. Therefore the static and dynamic shear strengths are difficult to compare as the level of confinement is not the same. Indeed, the confinement level is difficult to adjust as it depends on the dilatant behaviour of the concrete (increase of volume during the sample shear deformation) as well as the stiffness of the confinement cell. Finally the shear strength of concrete as function of the confining pressure is difficult to investigate with the oedo-PTS testing method.

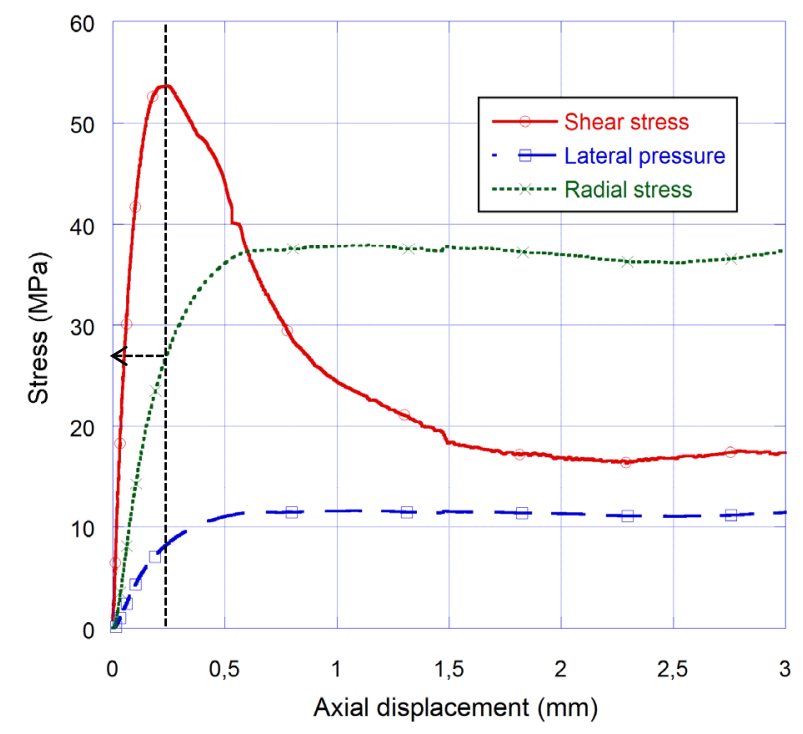

Fig. 2. Results of quasi-static oedo-PTS test performed on dry specimen. Strain-rate: $2^{\mathrm{e}}-5 / \mathrm{s}$, aluminium confining cell, concrete samples with radial notches.

It is the reason why a new testing technique was developed in 3SR laboratory based on a prestressed metallic ring with the aim to better control the confining level in the sheared sample. The principle of this testing method is explained in the next section. First results are given in the next part. The results are compared to those obtained with previous testing technique (passive confinement).

\section{The Pre-stressed PTS tests}

The principle of the proposed PS-PTS (Pre-Stressed Punch-Through-Shear) test is the following: an instrumented ring is deformed elastically by applying a compression load (Fig. 4a). When the ring is enough deformed the concrete sample is inserted into the ring. To increase or adjust the level of pre-stress along the concrete sample thin metallic sheets are placed in- between the ring and the sample. Next, the compression load applied to the ring is released (Fig. 4b) so the concrete sample is subjected to a confinement along the direction $(\vec{x})$ (load (1) in Fig. 4c).

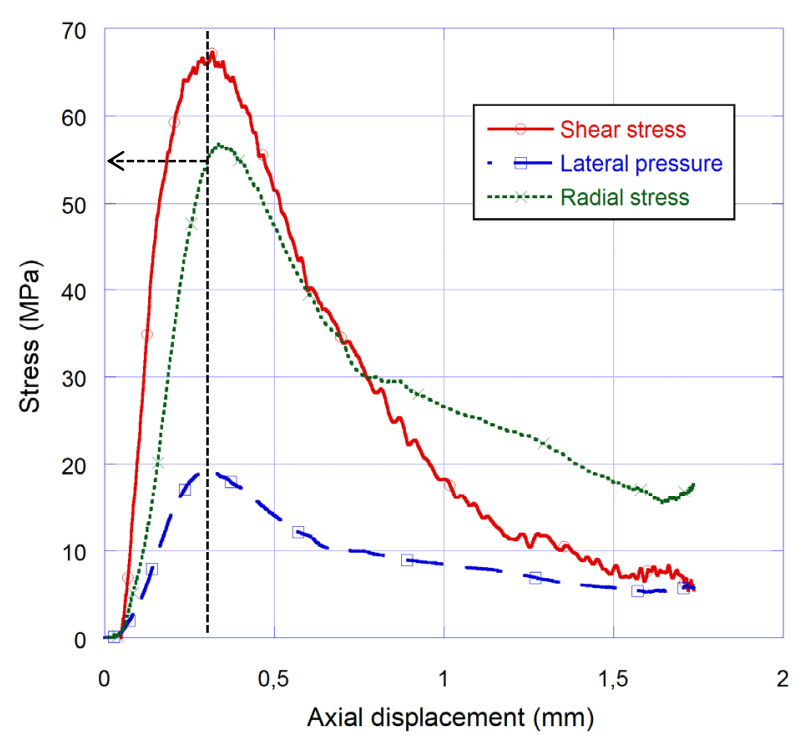

Fig. 3. Results of dynamic oedo-PTS test performed on dry specimen. Strain-rate: $60 / \mathrm{s}$, aluminium confining cell, concrete samples with radial notches.
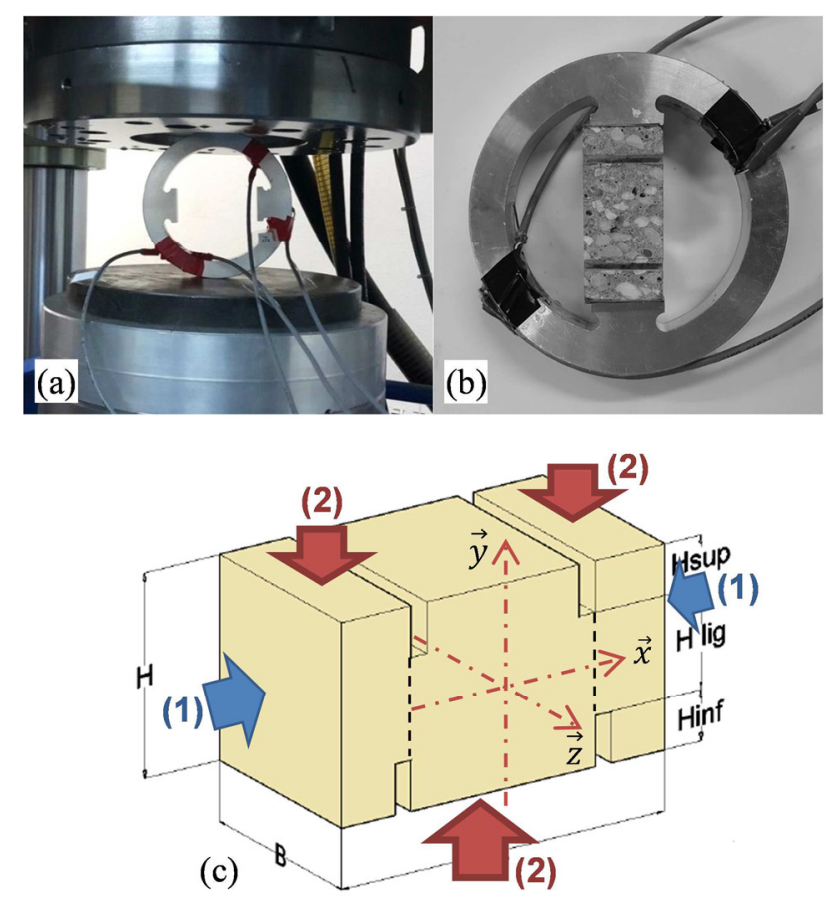

Fig. 4. The 3 loading stages of the PS-PTS test. (a) A metallic ring is deformed elastically by applying a compression load. (b) The concrete sample is inserted into the ring and the compression load applied to the ring is released. (c) The central part of the concrete sample is subjected to a relative displacement toward the side parts so the ligament is sheared (load (2)).

In a third stage, the central part of the concrete sample is subjected to a relative displacement toward the side parts along the $(\vec{y})$ axis (loading (2) in Fig. 4a) so the ligament is sheared (dotted lines in Fig. 4c). 
The typical dimensions for the parallelepiped concrete sample are the following: the length is $\mathrm{L}=70$ $\mathrm{mm}$, the width and the height are respectively $\mathrm{B}=40$ $\mathrm{mm}, \mathrm{H}=40 \mathrm{~mm}$ and the ligament height is $\mathrm{H}_{\mathrm{lig}}=20 \mathrm{~mm}$ (Fig. 3c). The corresponding shear surface is equal to $\mathrm{S}_{\text {lig }}=2 \mathrm{xBxH}_{\text {lig }}=1600 \mathrm{~mm}^{2}$. The metallic ring was designed based on FE numerical simulations. So the following dimensions were chosen: the inner diameter is $50 \mathrm{~mm}$, the outer diameter is $65 \mathrm{~mm}$ so the mean radius is $\mathrm{R}=57.5 \mathrm{~mm}$ and the width is $\mathrm{b}=15 \mathrm{~mm}$. The thickness is set to $t=20 \mathrm{~mm}$. A ring made of aluminium alloy was used for small confinement level and another ring made of steel is used to reach higher confinement level.

The metallic ring was instrumented with 4 straingauges glued on its inner or outer surfaces. A calibration procedure was conducted by applying a compression load to the ring so the relationship between the applied force and the measured strain was set. Therefore, the contact force between the ring and the sample can be deduced from the data of strain-gauges so the change of mean normal (confinement) stress (cf. Fig. 4c) during the shear tests can be deduced.

$$
\overline{\sigma_{x x}}=\frac{F_{x}}{S_{l i g} / 2}
$$

The experimental results obtained in a PS-PTS test performed under quasi-static loading conditions are depicted on the Fig. 5. The test was conducted with the steel ring so the initial confinement level was set to $20 \mathrm{MPa}$. The mean shear stress is defined as:

$$
\overline{\sigma_{\text {shear }}}=\frac{F_{y}}{S_{\text {lig }}}
$$

The mean confinement stress and shear stress are plotted as function of the axial displacement measured by means of a LVDT (Linear Variable Displacement Transducer) extensometer (Fig. 5). The maximum mean shear stress reaches about $33 \mathrm{MPa}$. The mean confinement stress slightly increases during the tests up to $25 \mathrm{MPa}$ and next decreases during the shearing of the sample. The confinement stress at the peak of shear stress is about 24.5 MPa. However the change of confinement stress during the sample shearing is much smaller than in the oedo-PTS test (Fig. 2).

\section{Dynamic tests}

The dynamic PS-PTS tests were conducted by using a Split Hopkinson bar apparatus testing device. The set-up is composed of a striker bar of $480 \mathrm{~mm}$ in length and 45 $\mathrm{mm}$ in diameter, an incident bar of $1500 \mathrm{~mm}$ in length and $45 \mathrm{~mm}$ in diameter made of high-strength aluminium alloy and two output bars of $1200 \mathrm{~mm}$ in length and 20 $\mathrm{mm}$ in diameter. The cylindrical input and output bars are instrumented with strain-gauges which allow obtaining reliable records of the incident, reflected and transmitted stress pulses. A pulse shaper technique is used in order to get a force balance in the specimen. A thin disk of lead is attached on the impact end of the incident bar so it generates an incident wave characterized by a long rising time. The experimental setup is schematically shown in Figure 6.

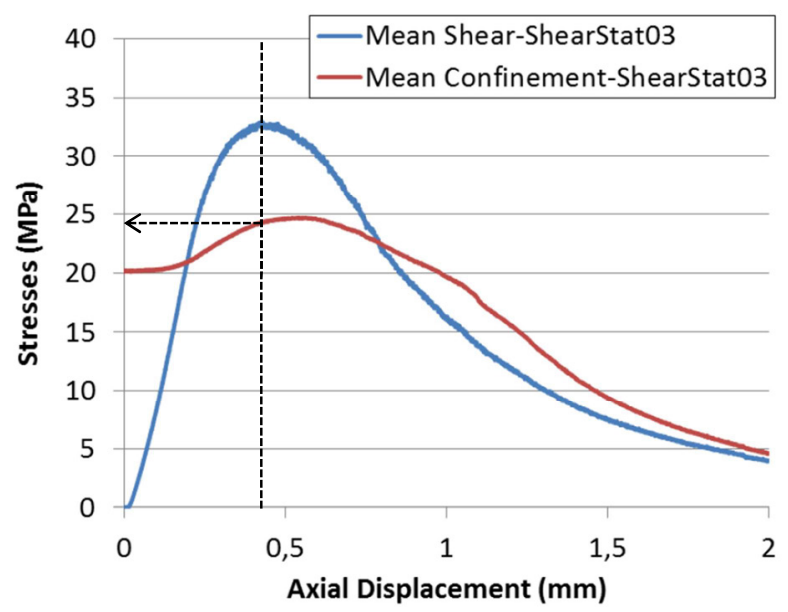

Fig. 5. Experimental results of a PS-PTS test performed on dry R30A7 under quasi-static loading with a steel confining ring.

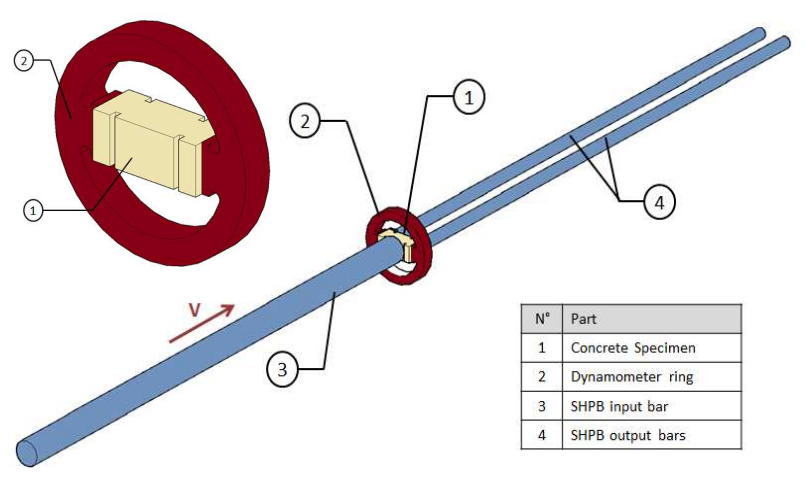

Fig. 6. Experimental set-up used in dynamic PS-PTS test.

A classical Kolsky processing was applied to the recorded incident, reflected and transmitted pulses on the input and output bars so the differential axial displacement of the sample and the input and output forces were deduced. The confinement level is measured thanks to the data of strain-gauges glued on the ring. The results of a dynamic PS-PTS test performed on dry R30A7 concrete are given in Fig. 7. The strain-rate was estimated around 80/s. As observed in quasi-static condition the shear stress increases until the peak and rapidly decreases after the peak. The maximum shear stress (45 MPa) is significantly higher compared to the value of shear strength noted under quasi-static loading condition (33 MPa). On the other hand, the confinement stress reached at the peak $(27.5 \mathrm{MPa})$ is very close to the confinement level noted under static loading condition (24.5 MPa). It is concluded that a significant increase of shear strength (about $36 \%$ ) is observed at elevated strainrate compares to the quasi-static loading condition.

\section{Conclusion}

A new testing experimental method is proposed to investigate the shear behaviour of concrete under quasistatic and dynamic loadings. This method called the PS- 
PST (Pre-Stressed Punch-Through-Shear) testing technique relies on the use of an "active" confining ring. To do so, the concrete specimen is inserted into a prestressed metallic cell. During the unloading stage of the cell, confining stresses are transferred to the ligament of the sample. In a second stage, a differential displacement applied to the central part of the sample toward the side parts produces a shearing of the ligament. Contrary to the previous oedo-PTS method that uses a passive confining ring, the present approach provides a much constant confinement level during the shear loading and this technique allows the confinement level to be better set by inserting small metallic sheets between the sample and the ring before the unloading stage.

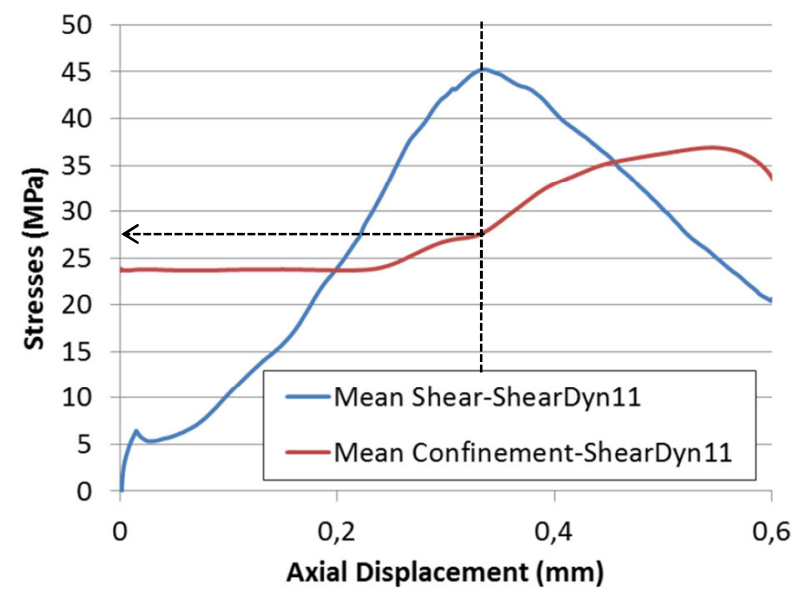

Fig. 7. Experimental results of a PS-PTS test performed on dry R30A7 under dynamic loading with a steel confining ring.

Shear experiments were conducted on dry R30A7 concrete under quasi-static condition by using a hydraulic press and under dynamic condition by using a SHPB testing facility. Whereas classical measurement techniques (LVDT and force cell in static test, classical Kolsky processing in dynamic test) provide the displacement and the shear stress in the ligament, the confinement stress is deduced from data of strain gauges attached to the ring. Finally, the obtained results show higher shear strength of dry R30A7 concrete in quasistatic than in dynamic experiments.

This work has been sponsored by CEA- Gramat (France). The support of this organization is gratefully acknowledged by the authors.

\section{References}

1. Li Q.M., Reid S.R., Wen H.M. Telford A.R., Local impact effects of hard missiles on concrete targets, Int J. Impact Eng. 32, 224-284 (2005)

2. Forquin P., Arias A., Zaera R. Role of porosity in controlling the mechanical and impact behaviours of cement-based materials, Int. J. Impact Eng., 35 (3), 133-146 (2008)

3. Forquin, P., Endommagement et fissuration de matériaux fragiles sous impact balistique, rôle de la microstructure. Ph.D. dissertation, Ecole Normale Supérieure de Cachan, France (2003) in French

4. Forquin P., Hild F.,Dynamic Fragmentation of an Ultra-High Strength Concrete during Edge-On Impact Tests, ASCE J Eng Mech, 134 (4), 302-315 (2008)

5. Watkins J., Fracture toughness test for soil-cement samples in mode II. Int. J. Fract. 23, 135-138 (1983)

6. Montenegro O., Sfer, Carol I., Characterization of concrete in mixed mode fracture under confined conditions. ICEM13 conference, Alexandroupolis, Greece (2007)

7. Forquin P., A. Arias, R. Zaera., An experimental method of measuring the confined compression strength of geomaterials, Int. J. Solids Struct., 44 (13), pp. 4291-4317 (2007)

8. Forquin P., G. Gary, F. Gatuingt, A testing technique for concrete under confinement at high rates of strain, Int. J. Impact Eng., 35 (6), 425-446 (2008)

9. P. Forquin, Influence of free water and strain-rate on the shear behaviour of concrete, Applied Mech. Mat., 82 pp. 148-153 (2011)

10. Forquin P., Sallier L., A Testing Technique to Characterise the Shear Behaviour of Concrete at High Strain-Rates. In: Chalivendra V., Song B., Casem D. (eds) Dyn. Behavior Mat., Volume 1, pp 531-536, DOI: 10.1007/978-1-4614-4238-7_68. Book series: Conf. Proc. Society for Exp. Mech. Series (Springer, NY. 2013)

11. Lukić B., Forquin P., Experimental characterization of the punch through shear strength of an ultra-high performance concrete. Int. J. Impact Eng., 91, 34-45. DOI: 10.1016/j.ijimpeng.2015.12.009 (2016). 